\title{
GAIA Level 2 Gestational Hypertension
}

National Cancer Institute

\section{Source}

National Cancer Institute. GAIA Level 2 Gestational Hypertension. NCI Thesaurus. Code C128010.

GAIA Level 2 Gestational Hypertension is defined by four criteria: first, the gestational age of the pregnancy must be greater than or equal to 20 weeks; second, a diagnosis of new onset maternal hypertension (systolic blood pressure greater than or equal to $140 \mathrm{mmHg}$ and/or diastolic blood pressure greater than or equal to $90 \mathrm{mmHg}$ ) that is sustained on two measurements for a minimum of one hour; third, the absence of any severe features (see preeclampsia with severe features category); fourth, the absence of proteinuria (as defined by urine dipstick result of negative or trace). 